\section{Audio Computer-Assisted Interview: uma nova tecnologia em avaliação de comportamento de risco em doenças sexualmente transmissíveis, HIV e uso de drogas}

\author{
Audio Computer-Assisted Interview: \\ a new technology in the assessment of sexually \\ transmitted diseases, HIV, and drug use
}

Anna Maria Azevedo Simões 1

Francisco Inácio Bastos 2

\footnotetext{
1 Centro Estadual de Tratamento e Reabilitação de Adictos, Secretaria de Estado de Saúde do Estado do Rio de Janeiro, Rio de Janeiro, Brasil. 2 Departamento de Informações em Saúde, Centro de Informação Científica e Tecnológica, Fundação Oswaldo Cruz, Rio de Janeiro, Brasil.

Correspondência A. M. A. Simões Centro Estadual de Tratamento e Reabilitação de Adictos, Secretaria de Estado de Saúde do Estado do Rio de Janeiro. Rua Dona Mariana 151, Rio de Janeiro, $R J$ 22280-020, Brasil. annago@uol.com.br
}

\begin{abstract}
Reliable responses are crucial when applying questionnaires on sensitive and stigmatized behaviors. This challenge has motivated researchers to develop new data collection methods. We conducted a systematic literature review on the implementation, effectiveness, reliability, and validity studies of ACASI (Audio ComputerAssisted Interview) in the assessment of drug use and sexual behavior. We reviewed 24 papers, none of which published by Brazilian researchers, and only three of which describing research implemented outside the United States. The studies showed that the computerized method is able to reduce psychological barriers linked to the collection of sensitive health-related information, thereby increasing its reliability. According to the surveys, the ACASI format is a fast and valid assessment method for large samples. ACASI generates databanks that can be easily processed and analyzed.
\end{abstract}

HIV; Street Drug; Sexually Transmitted Diseases; Sexual Behavior

\section{Introdução}

A avaliação de comportamento de risco para o vírus da imunodeficiência humana (HIV) e outras infecções transmitidas por relações sexuais desprotegidas e sangue, e sua eventual relação com o uso de álcool e drogas, constitui um desafio no âmbito da prevenção e tratamento de usuários de drogas e/ou populações vulneráveis a estas infecções. A preocupação mais freqüentemente citada diz respeito à fidedignidade das respostas obtidas por meio da aplicação de questionários de autopreenchimento e/ ou entrevistas face a face 1,2,3,4. As dúvidas de que as informações assim obtidas sejam, de fato, expressão dos comportamentos avaliados se referem tanto a uma possível dissimulação, e mesmo omissão, de aspectos da realidade, como a uma possível distorção e exagero nas respostas. A dissimulação ou omissão demonstraria um receio frente ao julgamento social de comportamentos passíveis de crítica ou estigma. $O$ exagero de algumas respostas pode estar relacionado à percepção do indivíduo de que precisa "agradar" o entrevistador, o que é conhecido na literatura em língua inglesa como "social desirability bias" 2,4,5,6,7.

Mesmo em ambientes onde existe maior privacidade, como em entrevistas clínicas de pacientes com seus médicos, Schottenfeld 8 menciona alguns fatores capazes de comprometer a acurácia da avaliação relativa ao uso 
de drogas. No que diz respeito ao paciente, por este, geralmente, querer minimizar seu problema; no que se refere à família, por esta resistir a se confrontar com um problema tão sensível; e no que se relaciona aos médicos e demais profissionais de saúde, devido às dificuldades de "rotular" os pacientes, ou, ainda, em função dos seus próprios hábitos de consumo de álcool/drogas ou conceitos morais.

$\mathrm{Na}$ área de pesquisa, diferentes modos de coleta de informações vêm sendo utilizados com o objetivo de minimizar tais vícios de informação. Entrevistas face a face, questionários de autopreenchimento, questionários feitos por telefone e computadorizados constituem as opções de que hoje dispomos. Cada um destes modos de coleta de informações tem suas vantagens e desvantagens. A necessidade de informações mais extensas e detalhadas exige, via de regra, a presença do entrevistador. Já a exigência de privacidade nas respostas aponta para o uso de questionários de autopreenchimento ou computadorizados. Pesquisas extensas e complexas, com grandes amostras, como as realizadas em domicílios, são facilitadas quando realizadas por telefone. No entanto, estes são apenas exemplos, que não restringem a utilização de nenhum dos métodos a esta ou aquela modalidade de estudo, ou que impeçam a utilização simultânea de duas estratégias de coletar dados, como, por exemplo, as entrevistas computadorizadas por telefone 9 . A variabilidade dos dados obtidos em função do modo de coleta pode ser exemplificada por estudos sobre o percentual de mulheres que relatam sexo anal, quando entrevistadas por entrevistadores ou por meio de questionários de auto-resposta. A variação encontrada nestes casos, por um grupo de pesquisadores norte-americanos 10 , foi de $6,0 \%$ vs. $13,0 \%$ de respostas afirmativas, respectivamente. Considerando que a probabilidade de transmissão do HIV é dez vezes mais elevada nas relações sexuais desprotegidas pênis-ânus do que nas relações desprotegidas pênis-vagina 11 , e que o sexo anal é alvo de preconceitos sociais, cabe ressaltar a importância de avaliações precisas da freqüência deste comportamento, levando-se em conta a necessidade de desenvolver campanhas de prevenção que abordem todas as modalidades de comportamento e práticas sexuais 12 .

A necessidade de minimizar os vícios das respostas obtidas com a utilização de questionários tem levado pesquisadores e profissionais da área de saúde a considerar métodos alternativos de coleta de informações, principalmente no que diz respeito a comportamentos passíveis de julgamento social desfavorável ou práticas consideradas ilegais.

\section{Metodologia}

O presente artigo procede a uma revisão sistemática da literatura internacional referente à implementação e utilização do ACASI (Audio Computer-Assisted Interview - Entrevista Computadorizada de Autopreenchimento), assim como estudos de validade e confiabilidade relacionados ao seu uso na avaliação e mensuração do consumo de drogas e/ou comportamento sexual.

A busca de artigos foi empreendida de dois modos: (a) por meio de busca bibliográfica na base de dados MEDLINE, referente aos anos 1970-2002; e (b) contato pessoal com pesquisadores que atuam na área. Apenas três estudos foram desenvolvidos fora dos Estados Unidos.

As palavras-chave utilizadas na busca dos artigos foram: (1) "audio computer assisted interview"; (2) "acasi" e (3) "a-casi", na sua interface com consumo de drogas, comportamento sexual, HIV/AIDS e infecções/doenças sexualmente transmissíveis (IST/DST). Não foram utilizados quaisquer critérios de exclusão. Apesar de não ter sido estabelecida qualquer restrição quanto à língua, somente foram encontrados artigos em inglês. A bibliografia nacional, apesar de exaustivamente pesquisada, não contribuiu com nenhum artigo, levando a pensar que esta metodologia não vem sendo utilizada em nosso meio, ou que, ao menos, nenhuma avaliação sistemática desta estratégia de coleta de dados foi completada até o momento.

Foram encontrados 27 artigos. Destes, foi possível obter 17 artigos. Dois foram excluídos por não terem como tema o estudo do ACASI relacionado à avaliação do uso de drogas e/ou do comportamento sexual. Outros sete artigos foram gentilmente cedidos por David Metzger, pesquisador da Universidade da Pensilvânia, Estados Unidos.

\section{Histórico e utilização do ACASI}

O primeiro estudo com questionários computadorizados, registrado pela literatura internacional, foi concluído em 1976/1977 1. Nas décadas de 80 e 90 , esta estratégia de coleta de informações se mostrou crescentemente relevante nas pesquisas em uso de drogas/DST/ HIV-AIDS por diferentes razões. As entrevistas com o uso de computadores têm demonstrado boa aceitabilidade, tanto para os entrevistados 
como para as equipes de pesquisa ou assistência $1,4,6,10,13,14,15,16$. A confiabilidade e validade desta modalidade de coleta de informações também se mostram elevadas 4,10,16,17,18,19,20. A busca pela qualidade tem aprimorado a tecnologia dos questionários por computadores, a partir de um uso inicial em telas de televisão 1 ou telas catódicas 5 , até o uso contemporâneo de laptops com respostas obtidas por toque na tela 15 , ou ainda, por telefone, onde as teclas do telefone funcionam como o teclado para as respostas 9 .

Atualmente, as entrevistas com uso de computadores são denominadas audio computerassisted self-interview (A-CASI, ACASI ou audio-CASI), e T-CASI, quando são realizadas via telefone.

Utilizando-se a tecnologia computadoriza$\mathrm{da}$, os participantes visualizam as perguntas e repostas na tela de um laptop, ouvem as mesmas perguntas e respostas em um fone de ouvido (headphone) e respondem as perguntas utilizando o teclado, o mouse ou com toques na própria tela. Este sistema apresenta diversas vantagens: o sistema de gravação das perguntas e respostas permite avaliar populações com baixo nível de escolaridade e padronizar as entrevistas; todos ouvem uma voz "padrão" e neutra (sem a influência gestual e de entonação dos entrevistadores) e respondem as mesmas questões, eliminando parte dos vícios das entrevistas tradicionais; a estratégia assegura ao respondente a privacidade de suas respostas; pode ser utilizado em diferentes línguas ao mesmo tempo e pode incorporar padrões de skip ("salto") de determinadas questões ou seções em questionários mais complexos, aumentando a consistência destes questionários.

Além disso, o ACASI gera um procedimento automático de entrada de dados, permitindo o manejo e análise precisa dos dados, eliminando os erros de entrada de dados, presentes em métodos convencionais de digitação.

A metodologia foi utilizada de forma pioneira, em um estudo randomizado, por Lucas et al. 1, para coleta de dados de usuários de álcool. Nesse estudo, uma entrevista clínica de rotina foi desenvolvida e apresentada em uma tela de televisão, sendo as respostas registradas em apenas três botões: "sim", "não" e "não entendi”. Os participantes do estudo - 36 homens de uma unidade de tratamento de problemas ligados ao álcool - foram também entrevistados por dois psiquiatras. Foram utilizados testes de concordância, comparando as diferentes entrevistas. Os resultados evidenciaram que a avaliação via computador era tão acurada quanto as avaliações dos psiquiatras. O estudo evi- denciou ainda que o consumo de álcool relatado era $30,0 \%$ maior quando os dados eram colhidos via computador, se comparados com as informações colhidas pelos psiquiatras. $\mathrm{O}$ artigo conclui que as chances de os pacientes fornecerem informações “difíceis” para um computador eram maiores do que para um médico.

Desde então, estudos têm sido conduzidos em diversos contextos e em diferentes populações: doadores de sangue 17; estudos de abrangência nacional (com relação aos Estados Unidos) com adolescentes 21,22; adolescentes no sistema penitenciário 23; mulheres sob risco, mas não infectadas pelo HIV 10; mulheres que freqüentavam uma clínica de planejamento familiar no Zimbábue, África 6; usuários de drogas em geral 16,18; usuários de drogas internados 19,24; usuários de drogas injetáveis que freqüentavam programas de troca de seringas 2,4 , 13,20; participantes de uma coorte preparatória para estudo de vacinas anti-HIV 25; homens que fazem sexo com homens 4 ; e estudantes na Tailândia 14,26.

Cabe ressaltar que apenas três desses estudos foram realizados fora dos Estados Unidos, um no Zimbábue 6 e dois na Tailândia 14,26.

\section{Estudos de aceitabilidade}

Em outras áreas da medicina, há muito tempo se utiliza a tecnologia computadorizada como ferramenta adicional em pesquisa, investigação diagnóstica ou tratamento, com ou sem a participação interativa do paciente. No entanto, uma das preocupações maiores no emprego do ACASI se refere à dificuldade que os entrevistados poderiam encontrar no manuseio de laptops, seu grau de familiaridade com esta nova linguagem e equipamento, e sua percepção quanto à privacidade deste modo de entrevista.

Observamos que, em nossos dias, a maioria das pessoas lida freqüentemente com terminais de computadores, mesmo que não disponham de um computador para seu uso pessoal. Terminais de banco, terminais de informação em prédios públicos, jogos eletrônicos, ou, pelo menos - para o conjunto de eleitores brasileiros - o momento da votação constituem alguns exemplos da utilização de terminais eletrônicos/microcomputadores na rotina diária da maioria das pessoas que vivem em centros urbanos.

Segundo Mills et al. 16 (p. 1): “o que hoje é denominado familiaridade básica com computadores (computer literacy) não constitui uma sofisticação social ou cultural, mas apenas a habilidade e capacidade de reconhecer e interpre- 
tar visualmente os sinais, caracteres ou imagens produzidos via tecnologia computadorizada".

Com o intuito de avaliar o impacto do uso do ACASI, alguns estudos vêm tematizando especificamente a aceitabilidade desta metodologia ou incluem como parte da sua implementação a avaliação da sua aceitabilidade entre os participantes, proporcionando uma maior adequação do uso do ACASI, e levando a avanços nos modos de aplicação em diferentes contextos e populações. A Tabela 1 resume alguns desses trabalhos.

A maioria dos participantes desses estudos mostrou-se favorável e/ou sentiu-se à vontade no uso dessa nova tecnologia 1,3,6,15, e afirmou mesmo preferir ser entrevistado pelo computador em futuras pesquisas 1,4,25. Com relação à privacidade, os dados variam de acordo com a comparação ACASI $v s$. entrevistador e ACASI $v s$. papel-lápis (autopreenchimento). Metzger et al. 4 encontraram que $60,2 \%$ dos usuários de drogas injetáveis e $58,7 \%$ dos homens que fazem sexo com homens, que responderam a um questionário de aceitabilidade, disseram ser mais "honestos" (fidedignos) nas respostas com o computador, se essas respostas forem comparadas às informações fornecidas a um entrevistador humano. No estudo de Navaline et al. $25,42,6 \%$ dos entrevistados não perceberam diferença em termos de privacidade/confidencialidade entre os modos ACASI e papel-lápis, e $39,7 \%$ disseram ser o computador mais privativo/confidencial. Com relação à honestidade (fidedignidade), 36,0\% responderam que as pessoas, de um modo geral, seriam mais "verdadeiras" em suas respostas ao computador, enquanto $10,3 \%$ acreditavam ser mais "verdadeiros" ao utilizar o modo papel-lápis.

Cooley et al. 15, em estudo utilizando ACASI por toque de tela, ACASI convencional e entrevistas face a face, relataram que $76,1 \%$ dos entrevistados consideraram o modo ACASI mais "privativo", enquanto $23,0 \%$ não mencionaram qualquer diferença entre os dois modos de entrevista. Gribble et al. 9, em estudo utilizando T-CASI e entrevistador humano por via telefônica, chamam a atenção para proporções consideravelmente mais elevadas de interrupção da entrevista com o T-CASI, uma vez que os entrevistados desligavam espontaneamente o telefone $(24,0 \%$ com o T-CASI $v$ s. $2,0 \%$ com entrevistador humano). Os autores consideraram que o fato dos entrevistados terminarem a entrevista no momento em que desejavam traduziria sua percepção de se sentirem mais à vontade quando a entrevista era feita por um computador do que quando as perguntas eram formuladas por um entrevistador, não se impor- tando, portanto, em ser "educados" com o computador, mas sim em ser verdadeiros.

Outro ponto a considerar sobre a aceitabilidade do ACASI é a interação da equipe de pesquisadores e entrevistadores com a tecnologia computadorizada. Todo estudo em que se utiliza o modo ACASI deve ser precedido de explanação aos entrevistados dos procedimentos para utilização do equipamento. Uma equipe não familiarizada com computadores ou que tema ser "trocada" pela nova tecnologia pode determinar efeitos profundos (o mais das vezes, negativos) sobre a maneira como os participantes reagem ao computador. $\mathrm{O}$ treinamento adequado e contínuo da equipe deve ser sempre considerado.

Segundo Mills et al. 16, o treinamento da equipe de pesquisa no manejo do ACASI não tem sido devidamente enfatizado, assim como não se tem procedido sistematicamente ao treinamento breve dos participantes da pesquisa antes de utilizar um computador.

A boa aceitabilidade do método ACASI registrada pelos diferentes estudos demonstra que a utilização da tecnologia computadorizada - cada vez mais presente na vida dos indivíduos comuns - encontra dificuldades substanciais, que impossibilitam o manuseio, ou problemas de compreensão apenas entre aqueles que apresentariam os mesmos problemas nas entrevistas face a face, como em indivíduos com sintomatologia psicótica ou alto nível de ansiedade 16 .

\section{Avaliação comparativa entre o ACASI e modos convencionais de entrevista}

Desde o estudo pioneiro de Lucas et al. 1, em que um relato mais freqüente de comportamentos passíveis de crítica social ou de sentimentos de vergonha foi observado com a utilização de computadores, diversos estudos têm sido realizados para testar esta hipótese. Esses estudos variaram em termos de contexto, de metodologia e também quanto ao seu tamanho amostral e população abrangida, além de diferentes formas de apresentação do ACASI. No entanto, o objetivo primordial foi e é sempre o de avaliar a precisão e confiabilidade dos dados coletados quando se utiliza o modo computadorizado em comparação aos modos tradicionais de entrevista (autopreenchimento, com entrevistador, ou via telefone). Alguns desses estudos estão resumidos na Tabela 2 .

O primeiro estudo que contou com amostras com adequado poder estatístico e representatividade foi realizado por Turner et al. 22, 
Estudos sobre a aceitabilidade do método ACASI, frente aos demais métodos de coleta de dados.

\begin{tabular}{|c|c|c|c|c|}
\hline Autor/Referência & Ano & Periódico & Método/População & Resultados \\
\hline Lucas et al. 1 & 1977 & Br J Psychiatry & $\begin{array}{l}\text { Questionário para avaliação de } \\
\text { aceitabilidade (autopreenchimento) } \\
\text { aplicado a } 37 \text { homens, usuários de álcool, } \\
\text { participantes de estudo comparativo entre } \\
\text { ACASI e entrevistas com psiquiatras. }\end{array}$ & $\begin{array}{l}\text { Entre os } 23 \text { homens que responderam o } \\
\text { questionário sobre aceitabilidade, } 75,0 \% \\
\text { foram favoráveis ao uso de computadores } \\
\text { em entrevistas. }\end{array}$ \\
\hline Davis \& Morse 19 & 1991 & Alcohol Clin Exp Res & $\begin{array}{l}199 \text { pacientes internados e } 98 \text { pacientes de } \\
\text { ambulatório em uma clínica especializada } \\
\text { responderam a uma entrevista face a face } \\
\text { sobre aceitabilidade em um estudo } \\
\text { comparativo ACASI vs. papel-lápis. }\end{array}$ & $\begin{array}{l}\text { O trabalho não apresenta dados numéricos. } \\
\text { Entrevistados referiram boa aceitação. Houve } \\
\text { críticas por parte dos entrevistados de que, } \\
\text { no computador, não se pode fornecer mais } \\
\text { detalhes. } \\
\text { Os autores concluíram haver maior custo- } \\
\text { efetividade do ACASI frente aos métodos } \\
\text { convencionais. }\end{array}$ \\
\hline Navaline et al. 25 & 1994 & $\begin{array}{l}\text { AIDS Res Hum } \\
\text { Retroviruses }\end{array}$ & $\begin{array}{l}26 \text { participantes de uma coorte preparatória } \\
\text { para teste de vacinas anti-HIV e } 42 \text { pacientes } \\
\text { de uma clínica de metadona responderam } \\
\text { a um questionário de autopreenchimento } \\
\text { após responderem a versões do ACASI e } \\
\text { papel-lápis do mesmo questionário. }\end{array}$ & $\begin{array}{l}75,0 \% \text { preferiram o modo computador. } \\
3,0 \% \text { relataram dificuldades no manuseio } \\
\text { do ACASI. } \\
43,0 \% \text { responderam não ver diferença em } \\
\text { termos de privacidade entre os dois modos, } \\
\text { mas apenas } 6,0 \% \text { escolheram o modo } \\
\text { papel-lápis. }\end{array}$ \\
\hline Kissinger et al. 3 & 1999 & Am J Epidemiol & $\begin{array}{l}280 \text { mulheres participantes de um estudo } \\
\text { comparativo entre ACASI vs. entrevista face } \\
\text { a face em uma clínica de planejamento } \\
\text { familiar e tratamento de DST participaram } \\
\text { de grupos focais de avaliação da } \\
\text { aceitabilidade. }\end{array}$ & $\begin{array}{l}71,0 \% \text { referiram sentirem-se à vontade com } \\
\text { o uso do A-CASI. }\end{array}$ \\
\hline $\begin{array}{l}\text { van de Wijgert } \\
\text { et al. } 6\end{array}$ & 2000 & Int J Epidemiol & $\begin{array}{l}221 \text { mulheres recrutadas em } 3 \text { diferentes } \\
\text { locais no Zimbábue, divididas em três } \\
\text { estratos de acordo com seu nível } \\
\text { educacional, responderam entrevista sobre } \\
\text { planejamento familiar no formato ACASI } \\
\text { e face a face, objetivando avaliar a } \\
\text { exeqüibilidade do método naquele } \\
\text { contexto. Responderam também a um } \\
\text { questionário face a face sobre aceitabilidade. }\end{array}$ & $\begin{array}{l}\text { Boa aceitação nos três estratos. Mulheres } \\
\text { com menor nível educacional tiveram } \\
\text { maiores problemas no manuseio do ACASI. } \\
\text { O coeficiente de concordância entre os dois } \\
\text { modos de entrevistas variou de } 65,0 \% \text { nas } \\
\text { entrevistadas de menor nível educacional, } \\
\text { a } 82,0 \% \text { no nível médio e } 84,0 \% \text { no nível } \\
\text { educacional mais elevado. }\end{array}$ \\
\hline Metzger et al. 4 & 2000 & Am J Epidemiol & $\begin{array}{l}847 \text { participantes, de um total de } 1.974 \\
\text { HSH e } 903 \text { UDI, de um estudo para } \\
\text { comparação entre ACASI vs. entrevista face } \\
\text { a face, responderam a um questionário } \\
\text { de autopreenchimento sobre aceitabilidade. }\end{array}$ & $\begin{array}{l}\text { Somente } 20,0 \% \text { relataram alguma } \\
\text { dificuldade com o ACASI. Tanto os UDI } \\
(60,2 \%) \text { quanto os HSH }(58,7 \%) \text { consideraram } \\
\text { que os entrevistados seriam mais honestos } \\
\text { nas respostas ao utilizarem o ACASI, } 37,0 \% \\
\text { preferiram o ACASI em futuros estudos, } \\
19,4 \% \text { a entrevista face a face e } 41,9 \% \text { não } \\
\text { souberam responder. }\end{array}$ \\
\hline Cooley et al. 15 & 2001 & $\begin{array}{l}\text { Comput Human } \\
\text { Behav }\end{array}$ & $\begin{array}{l}101 \text { participantes de estudo que avaliou } \\
\text { aceitação e confiabilidade de três modos } \\
\text { de aplicação de um mesmo questionário. } \\
\text { Todos respondiam aos três modos: ACASI } \\
\text { com respostas através de teclado, ACASI } \\
\text { com respostas por toque de tela e face } \\
\text { a face. Todos eram clientes de uma clínica } \\
\text { de tratamento de DST. }\end{array}$ & $\begin{array}{l}51,0 \% \text { preferiram o toque de tela, } 26,0 \% \text { o } \\
\text { modo teclado e } 23,0 \% \text { o modo face a face. } \\
\text { Entre os dois modos computadorizados, } \\
70,0 \% \text { disseram ser o toque de tela de mais } \\
\text { fácil manuseio. } \\
\text { Com relação ao modo que oferece maior } \\
\text { "privacidade" de resposta: } 49,0 \% \\
\text { consideraram o toque de tela, } 27,0 \% \\
\text { o ACASI tradicional e } 23,0 \% \text { não perceberam } \\
\text { diferença. }\end{array}$ \\
\hline
\end{tabular}

Legenda: ACASI ou A-CASI = Audio Computer-Assisted Interview; DST = doenças sexualmente transmissíveis;

$\mathrm{UDI}=$ usuário de droga injetável; $\mathrm{HSH}=$ homem que faz sexo com homem. 
Tabela 2

Estudos comparativos - confiabilidade do modo ACASI vs. modos convencionais de entrevista.

\begin{tabular}{|c|c|c|c|c|c|c|c|}
\hline $\begin{array}{l}\text { Autor/ } \\
\text { Referência }\end{array}$ & Ano & Periódico & $\begin{array}{l}\text { Natureza da } \\
\text { comparação }\end{array}$ & População & Metodologia & Resultados & Discussão \\
\hline Lucas et al. 1 & 1977 & $\begin{array}{l}\text { Br J } \\
\text { Psychiatry }\end{array}$ & $\begin{array}{l}\text { Computador vs. } \\
\text { entrevista com } \\
\text { psiquiatras }\end{array}$ & $\begin{array}{l}36 \text { homens } \\
\text { encaminhados por } \\
\text { seus clínicos para } \\
\text { uma unidade de } \\
\text { tratamento de } \\
\text { alcoolismo nos } \\
\text { Estados Unidos. } \\
\text { Nenhum havia } \\
\text { sido entrevistado } \\
\text { anteriormente por } \\
\text { psiquiatra. }\end{array}$ & $\begin{array}{l}\text { Cada participante } \\
\text { foi entrevistado } \\
\text { três vezes: através } \\
\text { do computador e } \\
\text { por dois psiquiatras. } \\
\text { A ordem das } \\
\text { entrevistas foi } \\
\text { randomizada. } \\
\text { Mesmo questionário } \\
\text { sobre problemas } \\
\text { com álcool nas três } \\
\text { coletas de dados. }\end{array}$ & $\begin{array}{l}\text { A discordância } \\
\text { entre os dois } \\
\text { psiquiatras foi de } \\
12,3 \% \text {, e entre } \\
\text { cada um deles e } \\
\text { o "computador", } \\
\text { de } 11,2 \% \text { e } 12,1 \% \text {, } \\
\text { respectivamente. } \\
\text { Nenhuma dessas } \\
\text { diferenças alcançou } \\
\text { significância } \\
\text { estatística (no } \\
\text { nível de } p=0,05 \text { ). }\end{array}$ & $\begin{array}{l}\text { A amostra muito } \\
\text { pequena não permite } \\
\text { descartar um erro do } \\
\text { tipo II. O modo } \\
\text { computadorizado } \\
\text { mostrou uma acurácia } \\
\text { no mínimo comparável } \\
\text { às entrevistas. } \\
\text { As quantidades } \\
\text { reportadas de álcool } \\
\text { foram } 30,0 \% \text { mais } \\
\text { elevadas no modo } \\
\text { computadorizado. }\end{array}$ \\
\hline Millstein 5 & 1987 & $\begin{array}{l}\text { Educ } \\
\text { Psychol } \\
\text { Meas }\end{array}$ & $\begin{array}{l}\text { Computador vs. } \\
\text { face a face vs. } \\
\text { autopreenchi- } \\
\text { mento }\end{array}$ & $\begin{array}{l}108 \text { adolescentes } \\
\text { do sexo feminino } \\
\text { de ambulatório } \\
\text { geral nos Estados } \\
\text { Unidos. }\end{array}$ & $\begin{array}{l}\text { Pacientes foram } \\
\text { randomizados para } \\
\text { um dos três modos. } \\
\text { Questionário sobre } \\
\text { comportamento } \\
\text { sexual, uso de } \\
\text { drogas, sintomas } \\
\text { ginecológicos. } \\
\text { Escala de reação } \\
\text { afetiva (com relação } \\
\text { ao último exame } \\
\text { ginecológico). }\end{array}$ & $\begin{array}{l}\text { A confiabilidade da } \\
\text { escala variou de } \\
\text { acordo com a } \\
\text { modalidade de } \\
\text { coleta de dados. } \\
\text { No modo } \\
\text { computadorizado } \\
\text { observou-se maior } \\
\text { consistência interna } \\
\text { (alfa de Cronbach) } \\
\text { das escalas afetivas, } \\
\text { o oposto do que } \\
\text { foi observado } \\
\text { com relação à } \\
\text { mensuração de } \\
\text { comportamentos } \\
\text { (maior consistência } \\
\text { interna quando } \\
\text { aplicadas por } \\
\text { entrevistador). } \\
\text { A análise de } \\
\text { variância não } \\
\text { evidenciou } \\
\text { diferenças dos } \\
\text { escores das escalas } \\
\text { referentes a } \\
\text { comportamentos, } \\
\text { mas evidenciou } \\
\text { diferenças } \\
\text { estatisticamente } \\
\text { significativas quanto } \\
\text { às escalas de } \\
\text { estados afetivos. } \\
\text { A ansiedade em } \\
\text { responder as } \\
\text { perguntas não se } \\
\text { mostrou diferente } \\
\text { nos três modos de } \\
\text { coleta. } \\
\text { A satisfação dos } \\
\text { entrevistados foi } \\
\text { maior no modo } \\
\text { computadorizado } \\
\text { e menor no face } \\
\text { a face. }\end{array}$ & $\begin{array}{l}\text { A comparabilidade } \\
\text { dos métodos quanto a } \\
\text { informações na área } \\
\text { comportamental } \\
\text { estaria relacionada ao } \\
\text { fato de que neste } \\
\text { setting perguntas } \\
\text { sobre comportamento } \\
\text { sexual, drogas e } \\
\text { problemas } \\
\text { ginecológicos são } \\
\text { habitualmente } \\
\text { formuladas. } \\
\text { Por outro lado, } \\
\text { perguntas da reação } \\
\text { afetiva ao exame } \\
\text { ginecológico não são } \\
\text { normalmente } \\
\text { formuladas, o que } \\
\text { explicaria as diferenças } \\
\text { observadas entre as } \\
\text { modalidades de } \\
\text { coleta. } \\
\text { O modo } \\
\text { computadorizado seria } \\
\text { apropriado para } \\
\text { reduzir a ansiedade } \\
\text { de pacientes } \\
\text { moderadamente } \\
\text { ansiosos, mas } \\
\text { constituiria uma } \\
\text { modalidade pouco útil } \\
\text { e mesmo } \\
\text { contraproducente para } \\
\text { pacientes com grande } \\
\text { ansiedade. }\end{array}$ \\
\hline
\end{tabular}

(continua) 
Tabela 2 (continuação)

\begin{tabular}{|c|c|c|c|c|c|c|c|}
\hline $\begin{array}{l}\text { Autor/ } \\
\text { Referência }\end{array}$ & Ano & Periódico & $\begin{array}{l}\text { Natureza da } \\
\text { comparação }\end{array}$ & População & Metodologia & Resultados & Discussão \\
\hline $\begin{array}{l}\text { Davis \& } \\
\text { Morse } 19\end{array}$ & 1991 & $\begin{array}{l}\text { Alcohol } \\
\text { Clin Exp } \\
\text { Res }\end{array}$ & $\begin{array}{l}\text { Computador vs. } \\
\text { autopreenchi- } \\
\text { mento (lápis-papel) }\end{array}$ & $\begin{array}{l}199 \text { pacientes } \\
\text { internados } \\
\text { (alcoolistas) ou } \\
\text { ambulatoriais de } \\
\text { clínica psiquiátrica } \\
\text { (sem história de } \\
\text { abuso de álcool). }\end{array}$ & $\begin{array}{l}\text { Todos responderam } \\
\text { o SAAST (instrumento } \\
\text { de triagem para } \\
\text { alcoolismo). } \\
\text { Seqüência de } \\
\text { aplicação alternada: } \\
\text { computador/papel- } \\
\text { lápis ou papel- } \\
\text { lápis/computador. }\end{array}$ & $\begin{array}{l}\text { Não foram } \\
\text { observadas } \\
\text { diferenças nos } \\
\text { resultados quando } \\
\text { a seqüência de } \\
\text { aplicação dos } \\
\text { instrumentos foi } \\
\text { invertida. } \\
\text { A acurácia do } \\
\text { instrumento foi algo } \\
\text { maior (sem } \\
\text { significância } \\
\text { estatística) no modo } \\
\text { computadorizado. }\end{array}$ & $\begin{array}{l}\text { As duas modalidades } \\
\text { de coleta são } \\
\text { equivalentes e o } \\
\text { instrumento se mostra } \\
\text { consistente em ambos } \\
\text { os formatos. }\end{array}$ \\
\hline $\begin{array}{l}\text { Locke et } \\
\text { al. } 17\end{array}$ & 1992 & JAMA & $\begin{array}{l}\text { Computador vs. } \\
\text { face a face }\end{array}$ & $\begin{array}{l}272 \text { indivíduos que } \\
\text { compareceram para } \\
\text { doação de sangue } \\
\text { em duas unidades } \\
\text { da Cruz Vermelha. }\end{array}$ & $\begin{array}{l}\text { Participantes } \\
\text { responderam a } \\
\text { questionário } \\
\text { padronizado da } \\
\text { Cruz Vermelha. } \\
\text { Seqüencia de } \\
\text { aplicação alternada: } \\
\text { computador/ } \\
\text { entrevista ou } \\
\text { entrevista/ } \\
\text { computador. } \\
\text { Avaliação de } \\
\text { aceitabilidade } \\
\text { através de } \\
\text { questionário pós- } \\
\text { doação. }\end{array}$ & $\begin{array}{l}\text { A seqüência de } \\
\text { aplicação não } \\
\text { influenciou as } \\
\text { respostas. } \\
\text { A aceitabilidade } \\
\text { do modo } \\
\text { computadorizado } \\
\text { foi muito boa. } \\
\text { Os voluntários } \\
\text { relataram mais } \\
\text { freqüentemente } \\
\text { comportamentos } \\
\text { de risco para a } \\
\text { infecção pelo HIV } \\
\text { no modo } \\
\text { computadorizado } \\
\text { (vs. entrevista). }\end{array}$ & $\begin{array}{l}\text { O modo } \\
\text { computadorizado teve } \\
\text { boa aceitação e os } \\
\text { voluntários relataram } \\
\text { comportamentos de } \\
\text { risco mais } \\
\text { freqüentemente } \\
\text { quando entrevistados } \\
\text { através desta } \\
\text { estratégia. }\end{array}$ \\
\hline Davis et al. 24 & 1992 & $\begin{array}{l}\text { Alcohol } \\
\text { Clin Exp } \\
\text { Res }\end{array}$ & $\begin{array}{l}\text { Computador vs. } \\
\text { entrevista face } \\
\text { a face }\end{array}$ & $\begin{array}{l}201 \text { pacientes } \\
\text { internados (usuários } \\
\text { de drogas) ou } \\
\text { ambulatoriais } \\
\text { (psiquiátricos). }\end{array}$ & $\begin{array}{l}\text { Seqüência de } \\
\text { aplicação alternada } \\
\text { de forma aleatória. } \\
\text { Questionário SUDDS } \\
\text { (diagnóstico de uso } \\
\text { de substâncias } \\
\text { psicoativas). }\end{array}$ & $\begin{array}{l}\text { A concordância } \\
\text { entre os modos de } \\
\text { coleta foi excelente, } \\
\text { com } 96,0 \% \text { de } \\
\text { concordância para } \\
\text { diagnóstico de } \\
\text { abuso/dependência } \\
\text { de álcool na vida e } \\
88,0 \% \text { de concordância } \\
\text { para abuso/ } \\
\text { dependência de } \\
\text { álcool no momento } \\
\text { da entrevista. } \\
\text { A validade do } \\
\text { instrumento no modo } \\
\text { computadorizado } \\
\text { frente à entrevista } \\
\text { clínica (padrão-ouro) } \\
\text { foi de } 100,0 \% \text { quanto } \\
\text { ao abuso/ } \\
\text { dependência } \\
\text { corrente e de } 71,0 \% \\
\text { quanto ao abuso/ } \\
\text { dependência de } \\
\text { drogas na vida. }\end{array}$ & $\begin{array}{l}\text { O instrumento (SUDDS) } \\
\text { é consistente e válido } \\
\text { quando aplicado sob } \\
\text { ambas as formas. }\end{array}$ \\
\hline
\end{tabular}

(continua) 
Tabela 2 (continuação)

\begin{tabular}{|c|c|c|c|c|c|c|c|}
\hline $\begin{array}{l}\text { Autor/ } \\
\text { Referência }\end{array}$ & Ano & Periódico & $\begin{array}{l}\text { Natureza da } \\
\text { comparação }\end{array}$ & População & Metodologia & Resultados & Discussão \\
\hline $\begin{array}{l}\text { Kissinger } \\
\text { et al. } 3\end{array}$ & 1999 & $\begin{array}{l}\text { Am J } \\
\text { Epidemiol }\end{array}$ & $\begin{array}{l}\text { ACASI vs. face } \\
\text { a face }\end{array}$ & $\begin{array}{l}280 \text { mulheres em } \\
\text { tratamento em clínica } \\
\text { de planejamento } \\
\text { familiar e DST, } \\
\text { integrantes de uma } \\
\text { coorte. }\end{array}$ & $\begin{array}{l}\text { Seqüência de } \\
\text { aplicação alternada. } \\
\text { Questionário com } \\
\text { perguntas sobre } \\
\text { comportamento } \\
\text { sexual, algumas } \\
\text { delas passíveis } \\
\text { de provocar } \\
\text { constrangimento. }\end{array}$ & $\begin{array}{l}\text { As mulheres } \\
\text { entrevistadas } \\
\text { responderam } \\
\text { questões passíveis } \\
\text { de estigmatização } \\
\text { mais freqüentemente } \\
\text { na modalidade } \\
\text { computadorizada } \\
\text { (frente à entrevista } \\
\text { face a face). } \\
\text { As diferenças de } \\
\text { resposta entre as } \\
\text { duas modalidades } \\
\text { de entrevista fizeram } \\
\text { com que as análises } \\
\text { multivariadas fossem } \\
\text { discrepantes } \\
\text { quando utilizaram } \\
\text { informações } \\
\text { coletadas por um e } \\
\text { outro método. }\end{array}$ & $\begin{array}{l}\text { O modo } \\
\text { computadorizado } \\
\text { revelou-se uma } \\
\text { estratégia fundamental } \\
\text { na minimização de } \\
\text { vícios ligados a "social } \\
\text { desirability" e } \\
\text { aumento da validade } \\
\text { de instrumentos que } \\
\text { avaliam questões } \\
\text { sensíveis e passíveis } \\
\text { de estigmatização. }\end{array}$ \\
\hline $\begin{array}{l}\text { Turner } \\
\text { et al. } 22\end{array}$ & 1998 & Science & $\begin{array}{l}\text { ACASI vs. } \\
\text { papel-lápis }\end{array}$ & $\begin{array}{l}\text { Amostra de } 1.690 \\
\text { adolescentes } \\
\text { americanos do } \\
\text { sexo masculino } \\
\text { de um estudo de } \\
\text { abrangência } \\
\text { nacional. }\end{array}$ & $\begin{array}{l}\text { Questionário sobre } \\
\text { comportamento } \\
\text { sexual, uso de } \\
\text { drogas, história de } \\
\text { DST, uso de armas } \\
\text { ou envolvimento } \\
\text { em situações de } \\
\text { violência. } \\
\text { Randomicamente } \\
\text { alocados na } \\
\text { proporção } 4 \text { ACASI: } \\
1 \text { papel-lápis. }\end{array}$ & $\begin{array}{l}\text { O relato de } \\
\text { comportamentos } \\
\text { socialmente } \\
\text { estigmatizados } \\
\text { (como utilizar } \\
\text { drogas injetáveis) } \\
\text { foi pelo menos } \\
\text { três vezes mais } \\
\text { freqüente entre os } \\
\text { entrevistados que } \\
\text { responderam } \\
\text { ao modo } \\
\text { computadorizado. } \\
\text { Em relação a outros } \\
\text { comportamentos de } \\
\text { risco que não são } \\
\text { objeto de tanta } \\
\text { recriminação social } \\
\text { (como fumar } \\
\text { maconha) observou- } \\
\text { se igualmente uma } \\
\text { maior freqüência, } \\
\text { ainda que não tão } \\
\text { pronunciada, } \\
\text { no modo } \\
\text { computadorizado. }\end{array}$ & $\begin{array}{l}\text { O modo } \\
\text { computadorizado } \\
\text { mostrou-se uma } \\
\text { estratégia fundamental } \\
\text { de aumento da } \\
\text { validade de } \\
\text { instrumentos com } \\
\text { respostas socialmente } \\
\text { estigmatizadas, } \\
\text { fornecendo um perfil } \\
\text { de risco bastante mais } \\
\text { acurado e revelador } \\
\text { de uma grave situação } \\
\text { social (freqüentemente } \\
\text { subestimada). }\end{array}$ \\
\hline $\begin{array}{l}\text { Des Jarlais } \\
\text { et al. } 2\end{array}$ & 1999 & Lancet & $\begin{array}{l}\text { ACASI vs. face } \\
\text { a face }\end{array}$ & $\begin{array}{l}1.481 \text { participantes } \\
\text { de programas de } \\
\text { troca de seringas, } \\
\text { em quatro cidades } \\
\text { americanas. }\end{array}$ & $\begin{array}{l}\text { Amostra aleatória } \\
\text { de participantes de } \\
\text { programas de troca } \\
\text { de seringas, com } \\
\text { posterior alocação } \\
\text { randomizada nos } \\
\text { modos ACASI e } \\
\text { entrevista face } \\
\text { a face. } \\
\text { Questionário sobre } \\
\text { comportamentos de } \\
\text { risco para a infecção } \\
\text { pelo HIV. }\end{array}$ & $\begin{array}{l}\text { Comportamentos } \\
\text { estigmatizados como } \\
\text { a utilização de } \\
\text { equipamentos de } \\
\text { injeção de outros } \\
\text { UDI foram mais } \\
\text { freqüentemente } \\
\text { relatados no modo } \\
\text { computadorizado } \\
\text { (comparados à } \\
\text { entrevista face } \\
\text { a face). }\end{array}$ & $\begin{array}{l}\text { Embora não tenha } \\
\text { sido possível avaliar a } \\
\text { validade das } \\
\text { entrevistas, o modo } \\
\text { computadorizado se } \\
\text { mostrou bastante } \\
\text { superior quanto à } \\
\text { avaliação de } \\
\text { comportamentos de } \\
\text { risco nesta população. }\end{array}$ \\
\hline
\end{tabular}

(continua) 
Tabela 2 (continuação)

\begin{tabular}{|c|c|c|c|c|c|c|c|}
\hline $\begin{array}{l}\text { Autor/ } \\
\text { Referência }\end{array}$ & Ano & Periódico & $\begin{array}{l}\text { Natureza da } \\
\text { comparação }\end{array}$ & População & Metodologia & Resultados & Discussão \\
\hline $\begin{array}{l}\text { Metzger } \\
\text { et al. } 4\end{array}$ & 2000 & $\begin{array}{l}\text { Am J } \\
\text { Epidemiol }\end{array}$ & $\begin{array}{l}\text { ACASI vs. face } \\
\text { a face }\end{array}$ & $\begin{array}{l}528 \text { homens que } \\
\text { fazem sexo com } \\
\text { homens }(\mathrm{HSH}) \text { e } 418 \\
\text { UDI responderam } \\
\text { o ACASI. } \\
1.446 \mathrm{HSH} \text { e } 485 \\
\text { UDI responderam } \\
\text { entrevistas face } \\
\text { a face. }\end{array}$ & $\begin{array}{l}\text { Pacientes de um } \\
\text { conjunto de estudos } \\
\text { preparatórios de } \\
\text { vacinas anti-HIV, } \\
\text { em diversos locais } \\
\text { dos Estados Unidos. } \\
\text { Avaliação de perfis } \\
\text { de risco para a } \\
\text { infecção pelo HIV. }\end{array}$ & $\begin{array}{l}\text { Os HSH relataram, } \\
\text { de forma } \\
\text { consistentemente } \\
\text { mais elevada, } \\
\text { comportamentos de } \\
\text { risco socialmente } \\
\text { estigmatizados } \\
\text { no modo } \\
\text { computadorizado. } \\
\text { Entre os UDI, os } \\
\text { resultados foram } \\
\text { heterogêneos, com } \\
\text { relato mais freqüente } \\
\text { de alguns } \\
\text { comportamentos } \\
\text { estigmatizados no } \\
\text { modo ACASI (p. ex. } \\
\text { utilizar seringa usada } \\
\text { sem limpar } \\
\text { anteriormente), ou } \\
\text { equivalência dos } \\
\text { diferentes métodos } \\
\text { quanto a outros } \\
\text { comportamentos } \\
\text { (p. ex. } \\
\text { compartilhamento } \\
\text { de seringas e } \\
\text { agulhas). }\end{array}$ & $\begin{array}{l}\text { A aceitabilidade do } \\
\text { método ACASI foi } \\
\text { muito boa entre os } \\
\text { entrevistados. } \\
\text { Segundo a opinião dos } \\
\text { entrevistados e em } \\
\text { consonância com os } \\
\text { achados empíricos, o } \\
\text { ACASI se mostrou uma } \\
\text { estratégia importante } \\
\text { de melhoria da } \\
\text { qualidade dos dados } \\
\text { comportamentais e de } \\
\text { aumento de sua } \\
\text { fidedignidade. }\end{array}$ \\
\hline $\begin{array}{l}\text { Grible } \\
\text { et al. } 9\end{array}$ & 2000 & $\begin{array}{l}\text { Subst Use } \\
\text { Misuse }\end{array}$ & $\begin{array}{l}\text { ACASI via telefone } \\
\text { (T-CASI) vs. } \\
\text { entrevista telefônica } \\
\text { com entrevistador } \\
\text { humano }\end{array}$ & $\begin{array}{l}697 \text { entrevistas no } \\
\text { modo T-CASI e } 2.881 \\
\text { no modo telefone } \\
\text { com entrevistador, } \\
\text { feitas com HSH, de } \\
\text { quatro cidades } \\
\text { norte-americanas. }\end{array}$ & $\begin{array}{l}\text { Alocação } \\
\text { randomizada para } \\
\text { cada modo de } \\
\text { entrevista. } \\
\text { Questões sobre } \\
\text { comportamento } \\
\text { sexual, uso de } \\
\text { drogas e sintomas } \\
\text { depressivos. }\end{array}$ & $\begin{array}{l}\text { O consumo de } \\
\text { drogas e } \\
\text { comportamentos } \\
\text { associados (p. ex. } \\
\text { "obteve drogas em } \\
\text { troca de sexo") foi } \\
\text { relatado com maior } \\
\text { freqüência na } \\
\text { modalidade T-CASI. } \\
\text { As entrevistas foram } \\
\text { interrompidas mais } \\
\text { freqüentemente } \\
\text { pelos entrevistados } \\
\text { na modalidade } \\
\text { T-CASI. }\end{array}$ & $\begin{array}{l}\text { A estratégia T-CASI de } \\
\text { coleta de informações } \\
\text { se mostrou bastante } \\
\text { útil e mais fidedigna } \\
\text { quanto a } \\
\text { comportamentos } \\
\text { estigmatizados. } \\
\text { Por outro lado, a } \\
\text { interrupção mais } \\
\text { freqüente de } \\
\text { entrevistas na } \\
\text { modalidade T-CASI } \\
\text { representa um } \\
\text { problema a ser } \\
\text { investigado em futuras } \\
\text { investigações, e talvez } \\
\text { se deva ao fato do } \\
\text { entrevistado se sentir } \\
\text { mais à vontade na } \\
\text { entrevista com o } \\
\text { computador. }\end{array}$ \\
\hline Riley et al. 13 & 2001 & $\begin{array}{l}\text { Am J Respir } \\
\text { Crit Care } \\
\text { Med }\end{array}$ & $\begin{array}{l}\text { ACASI vs. entrevista } \\
\text { face a face }\end{array}$ & $\begin{array}{l}282 \text { participantes } \\
\text { de um programa de } \\
\text { troca de seringas } \\
\text { em Baltimore, } \\
\text { Estados Unidos, } \\
\text { avaliados quanto à } \\
\text { presença de } \\
\text { tuberculose, em } \\
\text { 1998/1999. }\end{array}$ & $\begin{array}{l}\text { Os primeiros } 190 \\
\text { fizeram a entrevista- } \\
\text { padrão para } \\
\text { avaliação de fatores } \\
\text { de risco para } \\
\text { tuberculose e HIV, e } \\
\text { os } 92 \text { subseqüentes } \\
\text { foram entrevistados } \\
\text { pelo ACASI. }\end{array}$ & $\begin{array}{l}\text { Na modalidade } \\
\text { ACASI houve relato } \\
\text { mais freqüente de } \\
\text { uso de drogas (como } \\
\text { maconha e heroína) e } \\
\text { de comportamentos } \\
\text { de risco associados } \\
\text { a esse consumo } \\
\text { (como uso } \\
\text { compartilhado de } \\
\text { diferentes drogas). }\end{array}$ & $\begin{array}{l}\text { A aparente maior } \\
\text { fidedignidade da } \\
\text { coleta de informações } \\
\text { pelo modo ACASI } \\
\text { torna esta estratégia } \\
\text { fundamental para a } \\
\text { avaliação de fatores de } \\
\text { risco para o HIV e } \\
\text { tuberculose nesta } \\
\text { população. }\end{array}$ \\
\hline
\end{tabular}

(continua) 
Tabela 2 (continuação)

\begin{tabular}{|c|c|c|c|c|c|c|c|}
\hline $\begin{array}{l}\text { Autor/ } \\
\text { Referência }\end{array}$ & Ano & Periódico & $\begin{array}{l}\text { Natureza da } \\
\text { comparação }\end{array}$ & População & Metodologia & Resultados & Discussão \\
\hline $\begin{array}{l}\text { Newman } \\
\text { et al. } 20\end{array}$ & 2002 & $\begin{array}{l}\text { Am J } \\
\text { Public } \\
\text { Health }\end{array}$ & $\begin{array}{l}\text { ACASI vs. face } \\
\text { a face }\end{array}$ & $\begin{array}{l}\text { Reanálise de dados } \\
\text { de pesquisa } \\
\text { empírica anterior } \\
\text { (Des Jarlais et al. 2). }\end{array}$ & $\begin{array}{l}\text { Classificação das } \\
\text { perguntas do } \\
\text { questionário } \\
\text { aplicado em três } \\
\text { grandes categorias: } \\
\text { (A) comportamentos } \\
\text { estigmatizados; } \\
\text { (B) comportamentos } \\
\text { "neutros"; (C) } \\
\text { distúrbios } \\
\text { psicológicos. }\end{array}$ & $\begin{array}{l}\text { Categoria A: foram } \\
\text { observadas } \\
\text { freqüências } \\
\text { significativamente } \\
\text { mais elevadas na } \\
\text { modalidade ACASI. } \\
\text { Categoria B: não } \\
\text { foram observadas } \\
\text { diferenças } \\
\text { estatisticamente } \\
\text { significativas entres } \\
\text { as duas modalidades. } \\
\text { Categoria C: foram } \\
\text { observadas } \\
\text { freqüências } \\
\text { significativamente } \\
\text { mais elevadas na } \\
\text { modalidade face } \\
\text { a face. }\end{array}$ & $\begin{array}{l}\text { Para perguntas } \\
\text { passíveis de } \\
\text { julgamento social, o } \\
\text { ACASI parece } \\
\text { constituir a } \\
\text { modalidade mais } \\
\text { adequada, por } \\
\text { favorecer a } \\
\text { privacidade do } \\
\text { entrevistado. } \\
\text { Para perguntas que } \\
\text { buscam avaliar o } \\
\text { estado emocional do } \\
\text { entrevistado, a } \\
\text { modalidade face a } \\
\text { face se mostrou mais } \\
\text { adequada, } \\
\text { possivelmente devido } \\
\text { à "impessoalidade" da } \\
\text { entrevista com o } \\
\text { computador. }\end{array}$ \\
\hline $\begin{array}{l}\text { Jennings } \\
\text { et al. } 23\end{array}$ & 2002 & $\begin{array}{l}\text { Int J STD } \\
\text { AIDS }\end{array}$ & $\begin{array}{l}\text { ACASI vs. face } \\
\text { a face }\end{array}$ & $\begin{array}{l}181 \text { adolescentes } \\
\text { do sexo masculino } \\
\text { e } 84 \text { do feminino } \\
\text { em tratamento para } \\
\text { uso de drogas, em } \\
\text { Miami, Estados } \\
\text { Unidos, 1998-2000. }\end{array}$ & $\begin{array}{l}\text { Aplicação de } \\
\text { instrumento breve } \\
\text { para avaliação de } \\
\text { risco para HIV/DST } \\
\text { e uso de drogas. } \\
\text { Não houve } \\
\text { randomização na } \\
\text { definição dos } \\
\text { grupos avaliados } \\
\text { com um e outro } \\
\text { instrumento. }\end{array}$ & $\begin{array}{l}\text { Os entrevistados } \\
\text { avaliados via ACASI } \\
\text { reportaram menos } \\
\text { freqüentemente } \\
\text { comportamento de } \\
\text { risco que aqueles } \\
\text { entrevistados face } \\
\text { a face. }\end{array}$ & $\begin{array}{l}\text { Os resultados vão de } \\
\text { encontro aos achados } \\
\text { anteriores que, quase } \\
\text { sem exceção, } \\
\text { observaram uma } \\
\text { freqüência maior de } \\
\text { comportamentos } \\
\text { socialmente } \\
\text { estigmatizados na } \\
\text { modalidade } \\
\text { computadorizada. } \\
\text { Possível vício devido a } \\
\text { não randomização. } \\
\text { Possível receio de } \\
\text { conseqüências legais } \\
\text { no modo computador } \\
\text { e influência favorável } \\
\text { de uma boa relação } \\
\text { com os entrevistadores. } \\
\text { Os achados sugerem } \\
\text { que o contexto e a } \\
\text { população são } \\
\text { importantes na escolha } \\
\text { do modo de aplicação. }\end{array}$ \\
\hline Ellen et al. 27 & 2002 & $\begin{array}{l}\text { J Adolesc } \\
\text { Health }\end{array}$ & $\begin{array}{l}\text { ACASI aplicado no } \\
\text { domicílio vs. } \\
\text { entrevista telefônica } \\
\text { com entrevistador }\end{array}$ & $\begin{array}{l}233 \text { adolescentes } \\
\text { afro-americanos } \\
\text { recrutados por } \\
\text { estudo anterior sobre } \\
\text { comportamento } \\
\text { sexual e fatores de } \\
\text { risco para HIV/DST. }\end{array}$ & $\begin{array}{l}\text { Randomicamente } \\
\text { alocados para o } \\
\text { telefone ou ACASI } \\
\text { aplicado no } \\
\text { domicílio. } \\
\text { Questionário sobre } \\
\text { risco frente ao } \\
\text { HIV/DST e uso de } \\
\text { drogas. }\end{array}$ & $\begin{array}{l}\text { Exceção feita à } \\
\text { atividade sexual nos } \\
\text { últimos três meses, } \\
\text { todos os demais } \\
\text { itens foram } \\
\text { respondidos de } \\
\text { forma equivalente } \\
\text { nas duas } \\
\text { modalidades. } \\
\text { Observou-se também } \\
\text { equivalência quanto } \\
\text { à satisfação dos } \\
\text { entrevistados com } \\
\text { ambos os métodos. }\end{array}$ & $\begin{array}{l}\text { A entrevista via } \\
\text { telefone, mais barata, } \\
\text { pode ser utilizada em } \\
\text { lugar do ACASI, sem } \\
\text { que sejam observados } \\
\text { vícios relevantes nesta } \\
\text { população quanto à } \\
\text { avaliação de perfil de } \\
\text { risco. }\end{array}$ \\
\hline
\end{tabular}

Legenda: ACASI ou A-CASI = Audio Computer-Assisted Interview; DST = doenças sexualmente transmissíveis;

$\mathrm{UDI}=$ usuário de droga injetável; $\mathrm{HSH}=$ homem que faz sexo com homem. 
nos Estados Unidos, em 1998. Nesse estudo que comparou um questionário aplicado utilizando-se o método ACASI com uma versão do mesmo questionário autopreenchível, em uma amostra de 1.672 adolescentes masculinos foram evidenciadas freqüências significativamente mais elevadas de relato de comportamentos de risco e violência entre aqueles entrevistados que responderam a versão ACASI. As diferenças encontradas foram tão surpreendentes que os autores 22 (p. 871) mencionam no texto: "se este novo modo de avaliação fornece uma visão mais acurada dos padrões de comportamentos sexuais, uso de drogas e violência entre os adolescentes nos Estados Unidos, então os riscos são bem maiores do que supúnhamos".

Duas pesquisas subseqüentes, igualmente com amostras com adequado poder estatístico, foram desenvolvidas pelas equipes de Des Jarlais et al. 2 e Metzger et al. 4, ambos comparando o ACASI com entrevistas face a face em usuários de drogas injetáveis, no estudo de Des Jarlais, e homens que fazem sexo com homens e usuários de drogas injetáveis, no estudo de Metzger.

Ambos concluíram que a avaliação pelo modo ACASI possibilitou aos participantes relatar com maior fidedignidade comportamentos socialmente indesejáveis.

Grible et al. 9 testaram uma versão do T-CASI, comparando-a com entrevistas, com entrevistadores, também via telefone, encontrando dados semelhantes às pesquisas anteriores, no sentido de freqüências maiores de relato de uso de drogas e comportamentos sexuais de risco no modo T-CASI (frente às entrevistas com entrevistadores) numa população de 2.616 homens que fazem sexo com homens, na cidade de San Francisco, Estados Unidos. O estudo evidenciou claramente um relato mais freqüente de comportamentos de risco (especialmente aqueles mais estigmatizados) no modo T-CASI, com especial relevância quanto ao uso de crack, por ser esta uma droga de menor aceitação social. Já o uso de maconha foi relatado de forma relativamente similar nos dois modos, uma vez que a maconha é uma droga de maior aceitação e objeto de menor estigma social.

Em 2001, Riley et al. 13 utilizaram o ACASI para avaliação de fatores de risco para outra doença infecto-contagiosa, a tuberculose, encontrando também relatos mais freqüentes de diferentes comportamentos de risco para a tuberculose entre os entrevistados pelo ACASI.

Em 2001 e 2002, dois estudos desenvolvidos fora dos Estados Unidos 14,26 avaliaram, entre estudantes tailandeses, comportamentos de risco para HIV/DST, padrões de uso de drogas e comportamento sexual utilizando o ACASI, sob a argumentação de que este modo de entrevista minimizaria os vícios exatamente por conseguir captar mais precisamente comportamentos estigmatizados.

\section{Considerações finais}

Os estudos utilizando o formato de entrevista de autopreenchimento em computador (ACASI) têm evidenciado que este método é capaz de reduzir barreiras psicológicas no que se refere a perguntas sobre comportamentos socialmente indesejáveis.

Os estudos cujas comparações não evidenciaram diferenças estatisticamente significativas entre diferentes modos de coleta de informações 5,24,27 contaram com amostras menores (havendo, possivelmente, restrições quanto ao seu poder estatístico) e/ou não randomizadas (portanto, sujeitos a não comparabilidade dos grupos sob análise). No entanto, esses estudos, apesar de suas limitações, apontam também para a boa confiabilidade do ACASI enquanto estratégia de coleta de dados, com resultados, no mínimo, comparáveis às demais estratégias de coleta de informações.

Os estudos apresentados chamam a atenção para a possibilidade do ACASI apresentar confiabilidade mais elevada quando empregado na avaliação de comportamentos sociais indesejáveis, uma vez que proporcionaria aos entrevistados uma maior privacidade. Por outro lado, questionários utilizando entrevistadores parecem ser mais confiáveis no que concerne a perguntas vinculadas a estados emocionais ou ao relato de sintomas psicológicos, que, devido à sua complexidade intrínseca, se beneficiariam da interação pessoal. Acredita-se que o caráter impessoal do computador não estimula o entrevistado a falar de sentimentos.

Os achados dos estudos corroboram a expectativa de utilização do ACASI enquanto um modo de coleta de dados que proporciona uma avaliação rápida e fidedigna de um grande número de participantes, e é capaz de gerar dados que possam ser rapidamente processados e analisados 


\section{Resumo}

A preocupação com a fidedignidade das respostas em questionários que envolvem comportamentos passíveis de julgamento, crítica ou estigma social tem levado pesquisadores a considerar métodos alternativos de coleta de informações. O presente artigo procede a uma revisão sistemática da literatura internacional referente à implementação, utilização, validade e confiabilidade do ACASI (Entrevista Computadorizada de Autopreenchimento), relacionadas à mensuração do consumo de drogas elou comportamento sexual. Foram analisados 24 artigos, nenhum deles refere-se a estudos feitos no Brasil e apenas três fora dos Estados Unidos. Os estudos têm evidenciado que este método é capaz de reduzir barreiras psicológicas e chamam a atenção para a possibilidade do ACASI apresentar confiabilidade mais elevada quando empregado na avaliação de comportamentos estigmatizantes. Os achados corroboram a expectativa do ACASI como um método que proporciona uma avaliação rápida e fidedigna de um grande número de participantes e sua utilidade na geração de dados que possam ser rapidamente processados e analisados.

HIV; Drogas Ilícitas; Doenças Sexualmente Transmissíveis; Comportamento Sexual

\section{Colaboradores}

A. M. A. Simões redigiu o artigo, enquanto F. I. Bastos o revisou e o corrigiu.

\section{Referências}

1. Lucas RW, Mullin PJ, Luna CBX, McInroy DC. Psychiatrists and a computer as interrogators of patients with alcohol-related illnesses: a comparison. Br J Psychiatry 1977; 131:160-7.

2. Des Jarlais DC, Paone D, Milliken J, Turner CF, Miller H, Gribble J, et al. Audio-computer interviewing to measure risk behaviour for HIV among injecting drug users: a quasi-randomised trial. Lancet 1999; 353:1657-61.

3. Kissinger P, Rice J, Farley T, Trim S, Jewitt K, Margavio V, et al. Application of computer-assisted interviews to sexual behavior research. Am J Epidemiol 1999; 149:950-4.

4. Metzger DS, Koblin B, Turner C, Navaline H, Valenti F, Holte S, et al. Randomized controlled trial of audio computer-assisted self-interviewing: utility and acceptability in longitudinal studies. Am J Epidemiol 2000; 152:99-106.

5. Millstein SG. Acceptability and reliability of sensitive information collected via computer interview. Educ Psychol Meas 1987; 47:523-31.

6. van de Wijgert J, Padian N, Shiboski S, Turner C. Is audio computer-assisted self-interviewing a feasible method of surveying in Zimbabwe? Int J Epidemiol 2000; 29:885-90.

7. Last JM, Spasoff RA, Harris SS, Thuriaux MM, editors. A dictionary of epidemiology. $4^{\text {th }}$ Ed. Oxford: Oxford University Press; 2000.

8. Schottenfeld RS. Assessment of the patient. In: Galanter M, Kleber HD, editors. Textbook of the substance abuse treatment. Washington DC: American Psychiatry Press; 1994. p. 25-35.

9. Gribble JN, Miller HG, Cooley PC, Catania JA, Pollack L, Turner CF. The impact of T-ACASI interviewing on reported drug use among men who have sex with men. Subst Use Misuse 2000; 35: 869-90.

10. Gross M, Holte SE, Marmor M, Mwatha A, Koblin BA, Mayer KH. Anal sex among HIV-seronegative women at high risk of HIV exposure. J Acquir Immune Defic Syndr 2000; 24:393-8.

11. Royce RA, Sena A, Cates Jr. W. Sexual transmission of HIV. N Engl J Med 1997; 336:1072-8.

12. Alves K, Sahfer KP, Caseiro M, Rutherford G, Falcao ME, Sucupira MC, et al. Risk factor for incident HIV infection among anonymous HIV testing site clients in Santos, Brazil: 1996-1999. J Acquir Immune Defic Syndr 2003; 32:551-9.

13. Riley ED, Chaisson RE, Robnett TJ, Vertefeuille J, Strathdee AS, Vlahov D. Used of audio computerassisted self-interviews to assess tuberculosis-related risk behaviors. Am J Respir Crit Care Med 2001; 164:82-5.

14. van Griensven F, Supawitkul S, Kilmarx PH, Limpakarnjanarat K, Young NL, Manopaiboon C, et al. Rapid assessment of sexual behavior, drug use, human immunodeficiency virus, and sexually transmitted diseases in Northern Thai youth using audio computer-assisted self-interviewing and noninvasive specimen collection. Pediatrics 2001; 108:E13.

15. Cooley PC, Rogers SM, Turner CF, Al-Tayyib AA, Willis G, Ganapathi L. Using touch screen audioCASE to obtain data on sensitive topics. Comput Human Behav 2001; 17:285-93. 
16. Mills A, Williams ML, Gordon C, Young P, Zhao Z, Rusek R, et al. Reliability and validity of an audioCASI data collection instrument and evaluation of comparability with face-to-face interviewing. Bethesda: National Institute on Drug Abuse Community Research Branch; 1996. (Final Report).

17. Locke SE, Kowaloff HB, Hoff RG, Safram C, Popovsky MA, Cotton DJ, et al. Computer-based interview for screening blood donors for risk of HIV transmission. JAMA 1992; 268:1301-5.

18. Williams ML, Freeman RC, Bowen AM, Zhao Z, Elwood WN, Gordon C, et al. A comparison of the reliability of self-reported drug use and sexual behaviors using computer-assisted versus face-toface interviewing. AIDS Educ Prev 2000; 12:199213.

19. Davis LJ, Morse RM. Self-administered alcoholism screening test: a comparision of conventional versus computer-administered formats. Alcohol Clin Exp Res 1991; 15:155-7.

20. Newman JC, Des Jarlais DC, Turner CF, Gribble J, Cooley P, Paone D. The differential effects of faceto-face and computer interview modes. Am J Public Health 2002; 92:294-7.

21. Crosby R, Leichliter JS, Brackbill R. Longitudinal prediction of sexually transmitted diseases among adolescents. Results from a national survey. Am J Prev Med 2000; 18:312-7.

22. Turner CF, Ku L, Rogers SM, Lindberg LD, Pleck $\mathrm{JH}$, Sonenstein FL. Adolescent sexual behavior, drug use, and violence: increased reporting with computer survey technology. Science 1998; 280: 867-73.
23. Jennings TE, Lucenko BA, Malow RM, Dévieux JG. Audio-CASI vs interview method of administration of an HIV/STD risk of exposure screening instrument for teenagers. Int J STD AIDS 2002; 13:781-4.

24. Davis LJ, Hoffmann NG, Morse RM, Luehr JG. Substance Use Disorder Diagnostic Schedule (SUDDS): the equivalence and validity of a computeradministered and an interviewer-administered format. Alcohol Clin Exp Res 1992; 16:250-4.

25. Navaline HA, Snider EC, Petro CJ, Tobin D, Metzger D, Alterman AI, et al. Preparations for AIDS vaccine trials. An automated version of the risk assessment battery (RAB): enhancing the assessment of risk behaviors. AIDS Res Hum Retroviruses 1994; 10 Suppl 2:S281-3.

26. Sattah MV, Supawitkul S, Dondero TJ, Kilmarx PH, Yong NL, Mastro TD, et al. Prevalence of and risk factors for methamphetamine use in Northern Thai youth: results of an audio-computer-assisted self-interviewing survey with urine testing. Addiction 2002; 97:801-8.

27. Ellen JM, Gurvey JE, Pasch L, Tschann J, Nanda JP, Catania J. A randomized comparison of A-CASI and phone interviews to assess STD/HIV-related risk behaviors. J Adolesc Health 2002; 31:26-30.

Recebido em 08/Ago/2003

Aprovado em 25/Mai/2004 